\title{
The role of competitive environment and strategy in the supply chain's agility, adaptability and alignment capabilities
}

\author{
Pedro Garrido-Vega and Macarena Sacristán-Díaz \\ Departamento de Economía Financiera y Dirección de Operaciones, \\ Universidad de Sevilla, Seville, Spain \\ José Moyano-Fuentes \\ Departamento de Organización de Empresas, Marketing y Sociología, \\ Universidad de Jaén, Jaén, Spain, and \\ Rafaela Alfalla-Luque \\ Departamento de Economía Financiera y Dirección de Operaciones, \\ Universidad de Sevilla, Seville, Spain
}

\begin{abstract}
Purpose - This paper analyses the way that the industry's competitive environment and the company's strategy influence the implementation of the supply chain's (SC's) triple-A capabilities (agility, adaptability and alignment). Two competitive environment variables are analysed: competitive intensity of the industry and complexity of the SC. Two opposing competitive strategies are also considered: cost and differentiation.

Design/methodology/approach - The hypotheses have been tested using data gathered via a questionnaire given to 277 Spanish manufacturing companies, and structural equation modelling has been used for the analysis. Findings - The results show that competitive intensity is the most influential factor followed by business strategy. SC complexity does not seem to affect agility. Moreover, although the competitive environment variables affect the business strategy, the latter has no mediating effects between the competitive environment and $\mathrm{SC}$ agility, adaptability and alignment capabilities.

Originality/value - This study presents new insights into the environmental and strategic drivers linked to the implementation of SC agility, adaptability and alignment capabilities and offers guidelines to managers involved in SC management.
\end{abstract}

Keywords Competitive environment, Business strategy, Triple-A supply chain, Supply chain agility, Supply chain adaptability, Supply chain alignment

Paper type Research paper

\section{Introduction}

The recently revitalised (Lee, 2021) triple-A supply chain (SC) conceptual framework developed by Lee (2004) emphasises the importance of orchestrating the agility, adaptability and alignment

(C) Pedro Garrido-Vega, Macarena Sacristán-Díaz, José Moyano-Fuentes and Rafaela Alfalla-Luque. Published by European Journal of Management and Business Economics Emerald Publishing Limited. This article is published under the Creative Commons Attribution (CC BY 4.0) licence. Anyone may reproduce, distribute, translate and create derivative works of this article (for both commercial and noncommercial purposes), subject to full attribution to the original publication and authors. The full terms of this licence may be seen at http://creativecommons.org/licences/by/4.0/legalcode

The authors acknowledge the financial support of Spanish Ministry of Science, Innovation and Universities (Research Projects PID2019-106577GB-I00 by MCIN/AEI/10.13039/501100011033 and PID2019-105001GB-I00/AEI), UJA-FEDER Andalusian Operational Program (Research Project 1261128) and PAIDI 2020-Junta de Andalucía (Research Projects PY20_01209 and P20-00794).

Received 13 January 2021 Revised 23 June 2021 Accepted 2 October 2021 environment and strategy on

SCM 
capabilities for SC effectiveness, which is essential for today's SCs (Cohen and Kouvelis, 2020). However, the contingency theory (CT) (Lawrence and Lorsch, 1967) states that contextual variables can affect the level of achievement or implementation of tools and business practices. Therefore, knowledge of the SC context is a key element for their adequate management.

Concerning contextual drivers, one of the most relevant aspects of the competitive environment is the intensity of the competition faced by the company. Among the consequences of intense competition are short product life cycles, product design sophistication, consistently high quality, cost reductions and customisation (Fynes et al, 2005). All these create a more volatile, turbulent, unpredictable and demanding market environment that seems to foment SC agility, adaptability and alignment (Lee and Ra, 2016). Another important characteristic of a competitive environment is the complexity of the SCs in which companies operate. Greater complexity is usually associated with greater uncertainty, which heightens the requirement to develop agility, adaptability and alignment capabilities when competing.

On the other hand, companies try to successfully address the competitive environment by designing an appropriate strategy. Thus, firms seek to gain a competitive advantage by developing their strategies in line with their respective environments. According to Fisher (1997), certain/predictable products require efficient SCs, whereas, uncertain/unpredictable products require the SCs to be responsive. According to the dynamic capabilities view (DCV) (Teece et al., 1997), as a set of complex capabilities might be difficult to develop and therefore difficult to replicate, the triple-A can generate a competitive advantage for the firm (Whitten et al., 2012; Machuca et al., 2021). Therefore, it seems reasonable to assume that the type of competitive strategy adopted by an organisation can shape the capabilities of the SC that it seeks to develop.

The triple-A SC framework has been mainly analysed with the focus on its impact on performance (e.g. Machuca et al., 2021; Gligor et al., 2020; Alfalla-Luque et al., 2018; Attia, 2016). This study contributes to SC management (SCM) research by analysing new drivers related to the competitive environment, in particular SC complexity and competitive intensity, and strategies as antecedents of the triple-A SC capabilities and by identifying the individual roles that these drivers have on each of the triple-A capabilities. Therefore, this study addresses three relevant research questions: (1) How does a company's competitive environment influence its triple-A SC capabilities? (2) How does the type of competitive strategy affect triple-A SC capabilities? (3) Does strategy play a mediating role between competitive environment and triple-A SC capabilities?

The paper is organised as follows. Section 2 reviews prior studies on triple-A SC and the drivers analysed in this study. Section 3 describes the methodology used. Section 4 presents the results. Section 5 discusses them. Section 6 states the main contributions and implications, identifies some limitations and offers suggestions for further research.

\section{Theoretical background and hypotheses \\ Theoretical framework}

This paper builds on two theories frequently applied in SCM and operations management (MacCarthy et al., 2016; Defee et al., 2010) and, specifically, in the triple-A SC research (e.g. Whitten et al., 2012; Alfalla-Luque et al., 2018; Dubey et al., 2018; Machuca et al., 2021): CT (Lawrence and Lorsch, 1967) and the DCV (Teece et al., 1997).

Lee (2004) established that SC efficiency is necessary, but only for companies that build agile, adaptable and aligned SCs (triple-A SC) to outstrip the competition. Nevertheless, CT suggests that firms align their performance priorities with their contextual factors. Hence, the context should play a role (i.e. as a driver or barrier) in the triple-A SC capabilities. Although many contextual factors might exist, Chi et al. (2009) highlight four key dimensions that shape a firm's environment: the degree of dynamism, complexity, diversity and munificence. Roscoe et al. (2020), Gligor (2016) and Gligor et al. (2015) have analysed some of these 
contextual factors, but only in relation to SC agility. This work will examine SC complexity and competitive intensity (inversely related to munificence) as antecedents of the triple-A capabilities.

A further theoretical foundation of this study can be found in the DCV framework. The traditional concept of dynamic capabilities, which were understood to be developed internally within the firm, has been extrapolated to the external level of the firm as "dynamic SC capabilities" (Aslam et al., 2018; Dubey et al., 2018). However, due to the emerging application of this concept to the SC context, the amount of research is limited and the literature on their theoretical underpinnings, in particular their antecedents, is still in the nascent stages (Aslam et al., 2020). Whitten et al. (2012) argued that agility, adaptability and alignment are organisational dynamic capabilities that lead to competitive advantage and are developed and updated to respond to changes in customer demand and the structures of markets and economies. Consequently, the value of dynamic capabilities is dependent on the context. In this line, Barreto (2010) concluded that research in the field of DCV should focus on the internal and external factors that can enable firms to realise the potential of their dynamic capabilities or prevent them from doing so. With respect to internal factors, the previous research states that strategic orientation helps build dynamic capabilities (Zhou and Li, 2010; Tuominen et al., 2004) since it guides a firm's interactions with its SC partners and thus influences the relative emphasis that companies put on achieving dynamic SC capabilities (Zhou and Li, 2010).

\section{Triple-A supply chain}

Gaining a competitive advantage is a priority for firms to survive in the highly competitive global context (Marin-Garcia et al., 2018), where competition is not company-based, but SCbased. Therefore, SCs must be designed to achieve advantages over their competitors. According to Lee (2004, 2021), achieving a sustainable competitive advantage requires a triple-A SC. Agility, adaptability and alignment are capabilities that have been defined in a variety of domains (marketing, manufacturing, organisational, strategic, etc.) and are currently being developed in the SC domain.

SC agility has been defined as the capability to rapidly detect and respond to short-term changes in real demand and supply to generate or maintain a competitive advantage (Alfalla-Luque et al., 2018). An agile SC can adapt to market variations efficiently, respond to final demand quickly, produce and deliver products on time and cost-efficiently and generate an inventory reduction and external integration (Gligor and Holcomb, 2014; Swafford et al., 2006). SC adaptability can be defined as the capability to adapt strategies, products and/or technologies to structural market changes (Alfalla-Luque et al., 2018). Unlike agility, which is primarily related to decisions at the SC's tactical and operational levels, adaptability is a strategic-level attribute (Mak and Max Shen, 2020). A complex and uncertain market environment (economic, political, and social changes, demographic trends, changing consumer needs, global context and technological advances) requires an adaptable SC to improve the chance of survival (Tuominen et al., 2004). Finally, SC alignment is the capability to share information, responsibilities and incentives with SC members to coordinate activities and processes (Alfalla-Luque et al., 2018). This holistic focus considers the SC as a single entity (Lee, 2004) and implies strategic collaboration between the different members, with coherent objectives, strategies and processes (Flynn et al., 2010).

Most of the previous research focuses on the impact of triple-A SC capabilities on performance, but only a small number of articles are focused on triple-A SC drivers (e.g. Dubey et al., 2018). Feizabadi et al. (2019) confirm the lack of a comprehensive triple-A SC framework and stress the need for research focused on the drivers of triple-A SC. In this sense, 
the present study analyses the roles played by the industry's competitive intensity, the SC's degree of complexity and the company's competitive strategy.

\section{Competitive intensity and the triple-A SC capabilities}

The literature states that, far from being atomistic entities, firms are embedded in a network of relationships that influence their competitive behaviour (Moyano-Fuentes and MartínezJurado, 2016; Ketchen et al., 2004). What stands out in this network is the struggle between firms to obtain the limited resources and information required for survival, which is known as competitive intensity (Carroll and Hannan, 2000). A higher degree of competitive intensity involves highly competitive pressures, fast and unpredictable competitive moves and monitoring competitors (Hallgren and Olhager, 2009). Collectively, these factors create a volatile and demanding market environment in which customers find greater numbers of potential choices available and are free to switch to other firms (Heirati et al., 2016).

Fynes et al. (2005) found that in contexts of high competitive intensity, companies need to continuously monitor market changes and manage the SC accordingly. SCs operating in highly competitive industries are likely to have a greater need to ensure a sustainable competitive advantage at the SC level than those operating in stable industries. In other words, competitive intensity should be positively related to all the triple-A SC capabilities.

In settings of high-competitive intensity, firms need to adapt to changes in demand and modify their products (Fynes et al., 2005) and delivery times accordingly. The characteristic turbulence of this business environment leads to an agile SC being an essential feature of management, not only for the individual chain constituents but for the entire SC. Agile SCs outperform less-agile SCs by "assisting firms in improving their capability of collaboration, process integration and information integration" (McCullen et al., 2006). So, agile SCs provide value by mitigating risks in the competitive landscape and through rapid response measures (Braunscheidel and Suresh, 2009). Therefore, the following hypothesis is proposed:

\section{H1a. Competitive intensity is positively related to SC agility.}

On the other hand, competitive intensity is an external driver that can be used to act on strategic positioning (Hallgren and Olhager, 2009) as it can influence SC adaptability, that is, the ability to reshape the SC to add value for the customer (Ketchen et al., 2008). SC adaptability emphasises the need to sense changes in the $\mathrm{SC}$ and to be flexible when addressing them (Eckstein et al., 2015). Since SC adaptability prepares SC members to adjust to the situation and gain the desired competitive advantage (Dubey et al., 2018), an adverse environment of high competitive intensity would be expected to be positively related to SC adaptability. Consequently, the following hypothesis is formulated:

$H 1 b$. Competitive intensity is positively related to SC adaptability.

Lastly, competitive intensity determines inter-firm knowledge acquisition and has led organisations to reassess the need for cooperative, mutually beneficial SC partnerships to improve business performance (Flynn et al., 2010). An intense rivalry environment encourages SC partners to seek an opportunity for collaboration to develop competitiveness (Wu et al., 2017). The goal is to achieve effective and efficient flows of information, products, services and money to provide maximum value to customers (Moyano-Fuentes and Martínez-Jurado, 2016). Furthermore, information flow integration provides the basis for financial and physical flow integration (Sacristán-Díaz et al., 2018). A context of high competitive intensity is what makes the benefits of collaboration with SC partners more positive (Heirati et al., 2016), so the following hypothesis is formulated:

H1c. Competitive intensity is positively related to SC alignment. 
Complexity is inherent in management, but the shift from managing an organisation internally to managing the SC entails a major increase in the level of complexity that needs to be addressed. Blecker et al. (2005) state that, in most cases, SCs operate in dynamic environments with multiple connections between companies, so they are exposed to many sources of complexity. There is also a consensus that SCs have become more complex over recent years (Bode and Wagner, 2015).

The term complexity is a multidimensional and multidisciplinary concept, so there is no commonly accepted definition (Blecker et al., 2005). Following Manuj and Sahin (2011), SC complexity can be defined as "the structure, type and volume of interdependent activities, transactions, and processes in the supply chain that also includes constraints and uncertainties under which these activities, transactions and processes take place" (p. 523). According to Bode and Wagner (2015), two qualities of complexity (structure and behaviour) are usually distinguished. The first is static complexity (also called structural or detail complexity) and refers to the number and variety of elements that define the system. The second is dynamic complexity (or operational complexity) and refers to the interactions between the elements of the system.

Despite prior research on SC complexity being relatively scarce, Blome et al. (2014) indicate that the predominant, overall conclusion on the SC's upstream side is that greater supply complexity negatively influences performance. Manuj and Sahin (2011) warn that a lack of understanding of the drivers of complexity and poorly designed and executed strategies to address complexity in SCs often lead to undesirable outcomes. Bode and Wagner (2015) synthesise this in three outcomes: a decrease in operational performance, more complicated decision-making and the triggering of disruptions. The present study argues that the triple-A SC capabilities can also be affected by SC complexity.

Several authors claim that complexity and agility are inversely related. The main argument is that a less complex firm is easier to change and consequently more agile, so complexity has been used as a surrogate measure for agility (Sherehiy et al., 2007; Arteta and Giachetti, 2004). This argument can be extended to the SC, where Christopher (2000) states that complexity is argued to be a barrier to achieving SC agility. Likewise, Prater et al. (2001) state that agility should decrease as the exposure of the SC to uncertainty and complexity increases. Therefore, we propose the following hypothesis:

$H 2 a$. SC complexity is negatively related to SC agility.

As for SC adaptability, some authors propose that SC complexity can lead organisations to develop adaptability capabilities (Manuj and Sahin, 2011), and, as globalisation increases the complexity that affects the SC, adaptability is increasingly crucial (Hoole, 2005). Meanwhile, other authors state that complexity hinders the ability of a firm to react to change by reconfiguring its products, processes or organisational structure (Sherehiy et al., 2007). Given these contradictory antecedents, we tentatively propose the following hypothesis:

$H 2 b . \mathrm{SC}$ complexity is positively related to $\mathrm{SC}$ adaptability.

Regarding SC alignment, Fawcett and Magnan (2001) consider network complexity to be a barrier, and alignment mechanisms to be one of the most important bridges to effectively achieving SC integration. Gimenez et al. (2012) consider SC integration is only effective in a context characterised by high supply complexity. In the same line, Wong et al. (2015) find that $\mathrm{SC}$ information integration is more useful when firms work with many partners to market a wide variety of products, i.e. in the case of high market complexity. Hence, we hypothesise that: 


\section{Competitive strategy and the triple-A SC capabilities}

Sousa and Voss (2008) highlight the role of strategic context as one of the contingency factors traditionally considered in operations management and state the relevance of the fit between the production system and the organisation's priorities. In contrast, as stated previously, research in the DCV field suggests that both external and internal factors need to be focused on to enable firms to realise the potential of their dynamic capabilities (Barreto, 2010). Among these internal factors, the choice of competitive strategy, in the Porterian sense of orientation towards cost leadership or differentiation, could benefit or hinder the development of the triple-A capabilities. Three different types of SC strategy are usually identified: lean, agile and leagile SCs, depending on whether the chain focuses on efficiency, differentiation or a combination of both (Christopher et al., 2006).

The connection between the company's competitive strategy and SC strategy has been analysed by various authors, who highlight that a fit between competitive strategy and SCM positively impacts firm performance (Hofmann, 2010). In this regard, a lean SC would be appropriate for a cost-leadership competitive strategy, whereas an agile $\mathrm{SC}$ would be suitable for a differentiation competitive strategy in which speed is the priority (Mason-Jones et al., 2000).

Gligor et al. (2015) state that SC researchers (e.g. Sebastiao and Golicic, 2008; Christopher et al., 2006) connect efficiency and waste minimisation strategies with lean management and suggest that agility is not linked to efficiencies to the same extent. In this regard, Hallgren and Olhager (2009) empirically find that, as suggested, agile manufacturing is negatively associated with a cost-leadership strategy. Thus, when a company follows a cost-leadership strategy, a lean SC strategy and lower levels of the triple-A SC capabilities should be expected. However, $\mathrm{SC}$ research provides no definitive empirical evidence to indicate that agile SCs cannot also be efficient, and arguments exist that suggest that the main difference between lean and agility appears to be related to the flexibility performance dimension, not cost (Gligor et al., 2015). Indeed, Qi et al. (2011) conclude that cost leaders tend to implement both lean and agile SC strategies, although their emphasis on an agile strategy is significantly greater in a volatile environment than in a stable environment. More recently, Qi et al. (2017) found that a lean $\mathrm{SC}$ is appropriate for firms with higher priorities on cost, quality and delivery strategies, but not flexibility. Therefore, the literature suggests that a cost strategy could be negatively related to the triple-A SC capabilities.

In contrast, Hallgren and Olhager (2009) investigate internal and external factors that drive the choice of lean (focused on efficiency) and agile (focused on flexibility) operations capabilities and their findings point to agile manufacturing being directly affected by a differentiation strategy. Indeed, empirical evidence exists that firms focusing on a differentiation strategy emphasise the agile SC strategy (Qi et al., 2011) and that an agile $\mathrm{SC}$ is appropriate for firms competing on the flexibility strategy (Qi et al., 2017). Thus, when a company follows a differentiation strategy, an agile SC strategy should also be required and, consequently, a higher level of the triple-A SC capabilities should be expected. So, the literature leads us to propose the corresponding hypothesis:

H3. A more differentiation-oriented business strategy (vs. cost) is positively related to the implementation of triple-A SC capabilities (H3a: agility, H3b: adaptability and H3c: alignment).

On the other hand, according to Porter (1980), a company's strategy is expected to respond to its competitive environment, and therefore, competitive intensity and SC complexity are expected to influence the competitive strategy's orientation. So, the impact of both of the 
environmental variables on triple-A capabilities may be mediated by the strategy adopted by the company. Consequently, we add two exploratory mediation hypotheses:

H4. Business strategy plays a mediating role in the influence of competitive intensity on the triple-A SC capabilities (H4a: agility, H4b: adaptability and H4c: alignment)

H5. Business strategy plays a mediating role in the influence of SC complexity on the triple-A SC capabilities (H5a: agility, H5b: adaptability and H5c: alignment)

Based on all the above, our research model is presented in Figure 1.

\section{Methodology}

Population, questionnaire and data gathering

The hypotheses were tested using data gathered via a questionnaire with items drawn from the literature and measured on Likert scales. A draft version of the questionnaire was tested by a panel of five internationally recognised experts, and a pilot study was then conducted with five heads of SCM to ensure that the item definitions were meaningful and comprehensive. This minimised response bias and ensured the quality and validity of the survey instrument.

A population of 2,650 Spanish manufacturing companies with at least 50 employees (to guarantee concern for SCM in the company (Sacristán-Díaz et al., 2018)) was established as the object of the study. The population framework was obtained from the SABI (Iberian Balance Sheet Analysis System) website. Companies were classified into sectors according to the CNAE catalogue (Spanish Standard Industrial Classification).

The data gathering method consisted of a telephone survey using a computerised system (computer-aided telephone interviewing, CATI) to contact all the companies in the sample. In addition, a web questionnaire was designed by the mid-point of the expected fieldwork period to make it easier for any remaining interviewees to respond. The fieldwork was carried out in 2018 during the January-July period. The final sample comprised 277 valid questionnaires (10.5\% response rate), with a sample error of $5.6 \%$, for a confidence level of $95 \%$ for $p=q=0.5$. This is an adequate sample for detecting small effect sizes $\left(f^{2}=0.02\right)$ with the usual significance $(\alpha=0.05)$ and statistical power $(1-\beta=80 \%)$ levels in business studies for a model with 3 predictor variables ( $\mathrm{G}^{*}$ Power 3.1.9.7).

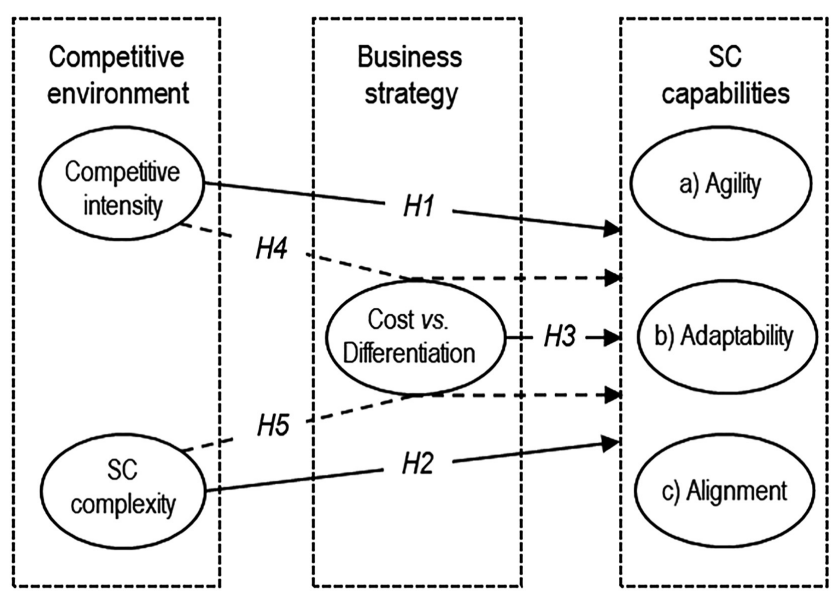

Figure 1. Research model 


\section{EJMBE}

Table 1.

Sample, population distribution of companies and response rate by industry
Table 1 shows the firm distribution in both the population and the sample according to the CNAE sector classification and a similar distribution of companies across the various sectors.

No evidence of response bias was found in a comparison of respondents with nonrespondents. No specific characteristics were observed in firms that decided not to participate and no pattern in the reasons that they gave to justify their refusal to take part. The first 40 responses and the last 40 responses were also compared, and no late response bias was found. Finally, the telephone survey responses and the web questionnaire responses were compared, and no significant differences were found for any of the study variables. With respect to common method variance, a full collinearity test (Kock, 2015) was conducted using WarpPLS 7.0 (Kock, 2020), and the obtained variance inflation factors (VIFs) ranged from 1.018 to 1.488, well under the level of 3.3 that would indicate problems. In sum, the data and analysis prove that the sample used in the study was randomly obtained and that it statistically represented the population.

\section{Measures}

The measures used in this study are all based on previous studies of similar topics to ensure their content validity. All the variables were targeted at one of three different respondents: SC or logistics manager, operations manager and CEO.

Competitive intensity. Competitive intensity was captured using the items adapted from Hallgren and Olhager (2009). Respondents were asked to indicate their opinions on a set of statements on a five-point Likert scale ranging from "strongly disagree" to "strongly agree".

SC structural complexity. Based on other studies (Roh et al., 2014; Bozarth et al., 2009), static or structural external complexity was measured by the number of suppliers and customers. As usual, these variables have been transformed with logarithms.

Competitive strategy. Following the Hallgren and Olhager (2009) study, cost leadership and differentiation (flexibility-based) have been measured using two items for each competitive strategy. Respondents were asked to indicate the relative importance of the four items (market and manufacturing goals) as an order-winning factor on a five-point Likert scale ranging from "absolutely crucial" to "least important". The two cost items were reversed to build this scale, so a low value indicates a cost strategy and a high value indicates a differentiation strategy.

\begin{tabular}{lcrrrr}
\hline & \multicolumn{3}{c}{ Population } & \multicolumn{3}{c}{ Sample } \\
Sector & Number & \multicolumn{1}{c}{$\%$} & Number & \multicolumn{1}{c}{$\%$} & Response rate \% \\
\hline Food products and tobacco & 543 & 20.49 & 48 & 17.33 & 8.84 \\
Chemicals and pharmaceutical products & 422 & 15.92 & 48 & 17.33 & 11.37 \\
Manufacture of metal products & 322 & 12.15 & 43 & 15.52 & 13.35 \\
Manufacture of machinery and equipment & 275 & 10.38 & 34 & 12.27 & 12.36 \\
Motor vehicles & 273 & 10.30 & 23 & 8.30 & 8.42 \\
Meat industry & 158 & 5.96 & 6 & 2.17 & 3.80 \\
Electrical machinery and materials & 141 & 5.32 & 14 & 5.05 & 9.93 \\
Manufacture of beverages & 106 & 4.00 & 7 & 2.53 & 6.60 \\
Furniture industry & 82 & 3.09 & 8 & 2.89 & 9.76 \\
Informatics, electronics and optics products & 81 & 3.06 & 13 & 4.69 & 16.05 \\
Manufacture of other transport material & 77 & 2.91 & 12 & 4.33 & 15.58 \\
Shoes and leather & 63 & 2.38 & 5 & 1.81 & 7.94 \\
Other manufacturing industries & 60 & 2.26 & 10 & 3.61 & 16.67 \\
Fabrics and textile & 47 & 1.77 & 6 & 2.17 & 12.77 \\
Total & 2,650 & 100 & 277 & 100 & 10.45 \\
& & & & &
\end{tabular}


Triple-A SC capabilities. SC agility items have been adapted from previous research on this topic (Qi et al., 2011; Tachizawa and Gimenez, 2010). SC adaptability and alignment scales have been adapted from Marin-Garcia et al. (2018). All items have been measured using a fivepoint Likert scale ranging from "strongly disagree" to "strongly agree".

\section{Role of environment and strategy on $\mathrm{SCM}$}

\section{Analysis}

The research model was tested using PLS-SEM (partial least squares-structural equation modelling) with WarpPLS 7.0 (Kock, 2020). PLS-SEM is a non-parametric, multivariate approach based on iterative ordinary least squares (OLS) regression that seeks to maximise the explained variance of endogenous latent constructs. PLS-SEM was chosen because, in this study, we are more interested in maximising the predictability of the dependent variables and understanding the variation in these explained by the dependent variables (i.e. PLS-SEM) than in evaluating how well the model fits our data set (CB-SEM). WarpPLS also allows the use of non-linear estimation algorithms, which are usually closer to reality.

\section{Results}

\section{Measurement model}

Evaluation of the goodness of the measurement model usually includes three criteria (Hair et al., 2017): internal consistency or reliability, convergent validity and discriminant validity. Some items in the original questionnaire were removed in this evaluation process following the Hair et al. (2017, pp. 112-115) criteria. Internal consistency has been evaluated by composite reliability, which ranges between 0.75 and 0.90 and always exceeds the minimum of 0.70 (see Table 2). Convergent validity at the construct level is measured by average variance extracted (AVE), which is above 0.50 in all the constructs except for business strategy, which is very close to this value (see Table 2).

Discriminant validity of the constructs has been verified with the Fornell-Larcker criterion, according to which the square root of each construct's AVE must be higher than its correlation with the other constructs. Table 3 shows that this criterion has been met. Additionally, discriminant validity is proven through the heterotrait-monotrait (HTMT) ratios (shown in the upper part of Table 3), and these are well below the most conservative threshold of 0.85 (Hair et al., 2019).

In view of the above, the measurement model can be stated to be acceptable.

\section{Structural model}

Once the measurement model has been validated, the structural model is evaluated and the research hypotheses are tested. The first measure used to validate the model as a whole is standardized root mean squared residual (SRMR). In this case, the value is 0.095 , which is below 0.1 and can be considered acceptable in the context of PLS (Kock, 2020).

As for the relationships in the structural model (the hypotheses), it can be observed in Table 4 that competitive intensity has a positive and significant impact $(p<0.001)$ on all the triple-A SC capabilities (H1a, H1b and H1c). SC structural complexity, however, positively affects SC adaptability and alignment - H2b and H2c $(p<0.05$ and $p<0.01)-$ but not SC agility $-\mathrm{H} 2 \mathrm{a}-$ even though the sign of the coefficient is negative, as hypothesised. Regarding business strategy, all three relationships are positive and significant, especially the relationships with SC agility and alignment $(\phi<0.001)$, and also with adaptability $(\phi<0.01)$. However, neither of the mediation relationships are significant ( $\mathrm{H} 4$ and $\mathrm{H} 5$ ), despite the strategy being significantly influenced by the two environmental variables.

Next, we evaluate the coefficients of determination of the endogenous constructs. The capabilities that are best explained by the model are SC alignment $\left(R^{2}=0.18\right)$ and SC 


\section{EJMBE}

\begin{tabular}{|c|c|c|c|c|c|}
\hline Latent variable & Item & Loadings & VIF & Composite reliability & AVE \\
\hline \multirow[t]{4}{*}{ Competitive intensity } & A11a & 0.784 & 1.562 & \multirow[t]{4}{*}{0.812} & \multirow[t]{4}{*}{0.525} \\
\hline & A11b & 0.854 & 1.795 & & \\
\hline & $\mathrm{A} 11 \mathrm{c}$ & 0.589 & 1.157 & & \\
\hline & A11d & 0.640 & 1.219 & & \\
\hline \multirow[t]{2}{*}{ SC complexity } & A2 & 0.777 & 1.046 & \multirow[t]{2}{*}{0.753} & \multirow[t]{2}{*}{0.604} \\
\hline & A7 & 0.777 & 1.046 & & \\
\hline \multirow[t]{4}{*}{ Business strategy } & A12ar & 0.781 & 1.374 & \multirow[t]{4}{*}{0.790} & \multirow[t]{4}{*}{0.487} \\
\hline & $\mathrm{A} 12 \mathrm{br}$ & 0.673 & 1.200 & & \\
\hline & $\mathrm{A} 12 \mathrm{c}$ & 0.640 & 1.184 & & \\
\hline & $\mathrm{A} 12 \mathrm{~d}$ & 0.689 & 1.230 & & \\
\hline \multirow[t]{6}{*}{ SC agility } & $\mathrm{C} 2 \mathrm{a}$ & 0.714 & 2.052 & \multirow[t]{6}{*}{0.873} & \multirow[t]{6}{*}{0.533} \\
\hline & $\mathrm{C} 2 \mathrm{~b}$ & 0.731 & 1.913 & & \\
\hline & $\mathrm{C} 2 \mathrm{c}$ & 0.709 & 1.512 & & \\
\hline & $\mathrm{C} 2 \mathrm{~d}$ & 0.708 & 1.805 & & \\
\hline & $\mathrm{C} 2 \mathrm{e}$ & 0.745 & 1.915 & & \\
\hline & $\mathrm{C} 2 \mathrm{f}$ & 0.773 & 1.771 & & \\
\hline \multirow[t]{4}{*}{ SC adaptability } & $\mathrm{C} 3 \mathrm{c}$ & 0.704 & 1.543 & \multirow[t]{4}{*}{0.846} & \multirow[t]{4}{*}{0.580} \\
\hline & C3d & 0.714 & 1.549 & & \\
\hline & C3e & 0.819 & 2.351 & & \\
\hline & C3f & 0.803 & 2.301 & & \\
\hline \multirow[t]{6}{*}{$\mathrm{SC}$ alignment } & $\mathrm{C} 4 \mathrm{c}$ & 0.779 & 1.847 & \multirow[t]{6}{*}{0.897} & \multirow[t]{6}{*}{0.594} \\
\hline & C4d & 0.789 & 2.080 & & \\
\hline & $\mathrm{C} 4 \mathrm{e}$ & 0.833 & 2.420 & & \\
\hline & C4f & 0.716 & 1.617 & & \\
\hline & $\mathrm{C} 4 \mathrm{~g}$ & 0.712 & 1.586 & & \\
\hline & $\mathrm{C} 4 \mathrm{j}$ & 0.787 & 1.899 & & \\
\hline
\end{tabular}

Reliability and convergent validity of latent variables

Note(s): All factor loadings are significant at $p<0.001$

\begin{tabular}{lcccccc}
\hline & 1 & 2 & 3 & 4 & 5 & 6 \\
\hline 1. Competitive intensity & 0.725 & 0.281 & 0.214 & 0.272 & 0.461 & 0.451 \\
2. SC complexity & 0.139 & 0.777 & 0.254 & 0.133 & 0.243 & 0.131 \\
3. Business strategy & -0.079 & 0.044 & 0.698 & 0.133 & 0.099 & 0.125 \\
4. SC agility & 0.195 & 0.026 & 0.072 & 0.730 & 0.389 & 0.514 \\
5. SC adaptability & 0.319 & 0.122 & 0.009 & 0.300 & 0.762 & 0.552 \\
6. SC alignment & 0.346 & 0.071 & 0.016 & 0.435 & 0.440 & 0.771 \\
\hline
\end{tabular}

Table 3.

AVE square root (diagonally), correlations between constructs (lower triangular part) and HTMT (upper triangular part) adaptability $\left(R^{2}=0.15\right)$. The value for SCagility $\left(R^{2}=0.08\right)$ is practically half that of the other two capabilities.

The $f^{2}$ has been used to analyse the size of the effects (Table 4 , last column). This is related to the practical significance of the coefficients rather than their statistical significance As can be seen, the size of the effect of competitive intensity on SC adaptability (0.10) and SC alignment (0.11) is small, and even smaller on SC agility (0.05). The effect of business strategy is quite small on all three As (0.04, 0.02 and 0.4 on agility, adaptability and alignment, respectively). The effect of SC structural complexity on SC adaptability and alignment is also close to the minimum ( 0.02 and 0.3 , respectively).

Finally, the Stone-Geisser $Q^{2}$ values, which measure out-of-sample predictive power, are above zero for all the endogenous constructs, which provides support for the predictive relevance of the model (Table 4). 


\begin{tabular}{|c|c|c|c|c|c|c|c|c|}
\hline \multicolumn{2}{|l|}{ Direct effects } & Coeff & Std. Dev & $p$-value & LCI 95\% & UCI 95\% & $f^{2}$ & $\begin{array}{r}\text { Role of } \\
\text { environment }\end{array}$ \\
\hline \multicolumn{2}{|c|}{ H1a: Competitive intensity $\rightarrow \mathrm{SC}$ agility } & 0.20 & 0.058 & $<0.001$ & 0.094 & 0.322 & 0.045 & and strategy on \\
\hline \multirow{2}{*}{\multicolumn{2}{|c|}{$\begin{array}{l}\text { H1b: Competitive intensity } \rightarrow \mathrm{SC} \text { adaptability } \\
\text { H1c: Competitive intensity } \rightarrow \text { SC alignment }\end{array}$}} & 0.30 & 0.057 & $<0.001$ & 0.197 & 0.421 & 0.104 & \\
\hline & & 0.32 & 0.057 & $<0.001$ & 0.212 & 0.435 & 0.113 & \\
\hline \multicolumn{2}{|c|}{ H2a: SC complexity $\rightarrow$ SC agility } & -0.05 & 0.060 & 0.180 & -0.171 & 0.062 & 0.005 & \\
\hline \multicolumn{2}{|c|}{ H2b: SC complexity $\rightarrow$ SC adaptability } & 0.12 & 0.059 & 0.021 & 0.005 & 0.236 & 0.021 & \\
\hline \multicolumn{2}{|c|}{ H2c: SC complexity $\rightarrow$ SC alignment } & 0.15 & 0.059 & 0.003 & 0.045 & 0.274 & 0.033 & \\
\hline \multirow{2}{*}{\multicolumn{2}{|c|}{$\begin{array}{l}\text { H3a: Business strategy } \rightarrow \text { SC agility } \\
\text { H3b: Business strategy } \rightarrow \text { SC adaptability }\end{array}$}} & 0.19 & 0.058 & $<0.001$ & 0.079 & 0.307 & 0.038 & \\
\hline & & 0.16 & 0.059 & 0.003 & 0.047 & 0.277 & 0.024 & \\
\hline \multicolumn{2}{|c|}{ H3c: Business strategy $\rightarrow$ SC alignment } & 0.18 & 0.058 & $<0.001$ & 0.075 & 0.303 & 0.036 & \\
\hline \multirow{2}{*}{\multicolumn{2}{|c|}{$\begin{array}{l}\text { Competitive intensity } \rightarrow \text { business strategy } \\
\text { SC complexity } \rightarrow \text { business strategy }\end{array}$}} & -0.11 & 0.059 & 0.025 & -0.232 & -0.001 & 0.012 & \\
\hline & & 0.13 & 0.059 & 0.013 & 0.016 & 0.246 & 0.016 & \\
\hline \multicolumn{2}{|l|}{ Indirect effects } & Coeff & Std. Dev & $p$-value & LCI $95 \%$ & UCI 95\% & $f^{2}$ & \\
\hline \multirow{6}{*}{\multicolumn{2}{|c|}{$\begin{array}{l}\text { H4a: } \mathrm{CI} \rightarrow \text { strategy } \rightarrow \text { SC agility } \\
\text { H4b: } \mathrm{CI} \rightarrow \text { strategy } \rightarrow \text { SC adaptability } \\
\text { H4c: } \mathrm{CI} \rightarrow \text { strategy } \rightarrow \text { SC alignment } \\
\text { H5a: } \mathrm{SC}-\mathrm{C} \rightarrow \text { strategy } \rightarrow \text { SC agility } \\
\text { H5b: SC-C } \rightarrow \text { strategy } \rightarrow \text { SC adaptability } \\
\text { H5c: SC-C } \rightarrow \text { strategy } \rightarrow \text { SC alignment }\end{array}$}} & -0.022 & 0.023 & 0.163 & -0.067 & 0.023 & 0.005 & \\
\hline & & -0.019 & 0.028 & 0.255 & -0.074 & 0.036 & 0.006 & \\
\hline & & -0.022 & 0.028 & 0.218 & -0.077 & 0.033 & 0.008 & \\
\hline & & 0.025 & 0.029 & 0.191 & -0.032 & 0.082 & 0.002 & \\
\hline & & 0.021 & 0.032 & 0.253 & -0.042 & 0.084 & 0.004 & \\
\hline & & 0.025 & 0.032 & 0.223 & -0.038 & 0.088 & 0.005 & \\
\hline \multicolumn{3}{|l|}{ Model estimation } & \multicolumn{2}{|c|}{$R^{2}$ adjusted } & \multicolumn{3}{|c|}{ Stone-geisser's $Q^{2}$} & \\
\hline Competitive strategy & \multicolumn{2}{|c|}{0.027} & \multicolumn{2}{|c|}{0.020} & \multicolumn{3}{|c|}{0.031} & \\
\hline SC agility & \multicolumn{2}{|c|}{0.078} & \multirow{2}{*}{\multicolumn{2}{|c|}{0.068}} & \multicolumn{3}{|c|}{0.087} & \\
\hline SC adaptability & & & 0.139 & & \\
\hline $\mathrm{SC}$ alignment & \multicolumn{2}{|c|}{0.182} & 0.1 & 173 & \multicolumn{3}{|c|}{0.177} & \\
\hline \multicolumn{8}{|c|}{$\begin{array}{l}\text { Note(s): CI: competitive intensity; SC-C: supply chain complexity; LCI: lower confidence interval; UCI: ppper } \\
\text { confidence interval. Values of } f^{2} \text { higher than } 0.020,0.150 \text { and } 0.350 \text { can be interpreted as small, medium and } \\
\text { large size effects, respectively }\end{array}$} & $\begin{array}{r}\text { Table } 4 . \\
\text { Structural model } \\
\text { results }\end{array}$ \\
\hline
\end{tabular}

\section{Discussion}

This research shows that the contextual variable with the strongest influence on the triple-A SC capabilities is competitive intensity (H1), which affects all three capabilities and has effects on SC adaptability and SC alignment that are approaching medium size. Thus, companies respond to higher competitive intensity with higher levels of SC agility, adaptability and alignment to add greater value for customers. A high level of competitive intensity encourages what Ketchen et al. (2008) call "best value SC".

As for the other analysed competitive environment variable - SC structural complexity (H2) - it can be seen that the higher the numbers of suppliers and customers in the SC, the more the companies seek to increase their SC adaptability and alignment capabilities, but SC agility is not affected. These results are in line with some previous studies. For example, Gimenez et al. (2012) found that SC integration (related to alignment) is only effective in buyer-supplier relationships characterised by high supply complexity. As for agility, Roscoe et al. (2020) found that SC complexity seems to have a limited impact on the effectiveness of internal process connectivity to enable $\mathrm{SC}$ agility. However, our results partially contradict Blome et al. (2014) as supply complexity negatively affects SC flexibility, which is related to SC agility. Some theoretical models (Serdarasan, 2013; Manuj and Sahin, 2011) show that other strategic and tactical variables can be used to manage complexity, and, perhaps because of this, the relationship between SC complexity and the triple-A SC capabilities is weaker. 
The obtained results also support our hypothesis (H3) regarding the expected influence of the company's business competitive strategy on the levels of the triple-A SC capabilities; the more differentiation-oriented the business strategy, the higher the implementation of the triple-A SC capabilities. These results build on those of other authors (Sebastiao and Golicic, 2008; Christopher et al., 2006) by highlighting the fact that cost strategy is much more rigid than differentiation strategy. Regarding the relationship between differentiation strategy and the triple-A SC capabilities, these results are also in line with the findings of other research (Qi et al., 2011, 2017; Hallgren and Olhager, 2009). However, these works focus on a single dimension (agility), while our work takes a more holistic approach and considers the effect of strategy on all three As.

Companies that seek competitiveness through triple-A SC capabilities need to be aware that the competitive environment and a differentiation-oriented strategy are drivers of these capabilities.

One interesting finding of our study is that company strategy does not seem to play any mediation role between the environmental variables and the triple-A capabilities ( $\mathrm{H} 4$ and $\mathrm{H} 5$ are rejected). This means that the competitive environment directly affects the triple-A, irrespective of the company strategy adopted and even though the environment influences the strategy in a differentiated way. Greater competitive intensity seems to be associated with a more cost-oriented strategy. However, greater SC structural complexity is positively related to a more differentiation-oriented strategy.

\section{Conclusions and further research}

Triple-A is essential for SC success (Cohen and Kouvelis, 2020), and it has become even more relevant (Erhun et al., 2020) due to the increasing turbulence and uncertainty in today's markets and economies. The major contribution of the present research is to empirically analyse the drivers that achieve triple-A SC capabilities through the lens of the CT and the DCV. This study, therefore, responds to the calls for further research focused on the drivers of the triple-A SC (Feizabadi et al., 2019); more contingency-based research to evaluate the fit between the environment, strategies and practices in the SCM context (Sousa and Voss, 2008); and, from the DCV, to analyse both the external and internal contextual factors on which the validity and effectiveness of the organisational capabilities might depend (Barreto, 2010). This work goes further by identifying how some contingent factors and competitive strategy are linked to the triple-A SC capabilities. The study results not only confirm the CT-based hypotheses that the context affects the triple-A capabilities but are also in line with the DCV in stating that these capabilities are dependent on the context.

Our findings have some interesting implications for managers. They show that when competitive intensity and SC structural complexity are high, triple-A SC capabilities may be necessary. They also show that the competitive strategy that the company pursues can determine the development of the triple-A capabilities. If the company focuses its competitive strategy on cost leadership, it will find it more difficult to develop agility, adaptability and alignment. It is also important to note that the influence of the competitive environment does not depend on the chosen strategy. So, SC managers should develop and manage SC agility, adaptability and alignment in light of external circumstances (i.e. competitive intensity and SC complexity) and the competitive strategic orientation of the company.

Individual analyses of the triple-A SC capabilities have determined the influence that the different drivers have on each of these. This will allow managers to take the most appropriate approach to improve of any of these capabilities. As the previous literature concludes, each of the triple-A SC capabilities has a specific effect on the different performance measures 
(Alfalla-Luque et al., 2018), which may lead managers to prioritise one over the others according to their business objectives.

This research has several limitations that can be viewed as directions for future research. The first is related to the use of a focal firm and its perceptions of SC relationships. A more general view of the SC involving informants from different companies would enable fuller and more accurate results to be obtained. Another limitation may be the way that some variables have been measured, especially SC complexity, which is a multifaceted concept, and competitive strategy, which is a construct that is difficult to approximate. Furthermore, the data that are used from Spanish industrial sectors, so it might be interesting to conduct a cross-country analysis to test this model for other countries.

\section{References}

Alfalla-Luque, R., Machuca, J.A.D. and Marin-Garcia, J.A. (2018), “Triple-A and competitive advantage in supply chains: empirical research in developed countries", International Journal of Production Economics, Vol. 203, pp. 48-61.

Arteta, B.M. and Giachetti, R.E. (2004), "A measure of agility as the complexity of the enterprise system”, Robotics and Computer-Integrated Manufacturing, Vol. 20 No. 6, pp. 495-503.

Aslam, H., Blome, C., Roscoe, S. and Azhar, T.M. (2018), "Dynamic supply chain capabilities", International Journal of Operations and Production Management, Vol. 38 No. 12, pp. 2266-2285.

Aslam, H., Blome, C., Roscoe, S. and Azhar, T.M. (2020), "Determining the antecedents of dynamic supply chain capabilities", Supply Chain Management, Vol. 25 No. 4, pp. 427-442.

Attia, A.M. (2016), "The effect of triple-A supply chain on performance applied to the Egyptian textile industry", International Journal of Integrated Supply Management, Vol. 10 Nos 3/4, pp. 225-245.

Barreto, I. (2010), "Dynamic capabilities: a review of past research and an agenda for the future", Journal of Management, Vol. 36 No. 1, pp. 256-280.

Blecker, T., Kersten, W. and Meyer, C.M. (2005), "Development of an approach for analyzing supply chain complexity", in Blecker, T. and Friedrich, G. (Eds), Mass Customization. Concepts - Tools - Realization, Gito Verlag, Klagenfurt, pp. 47-59.

Blome, C., Schoenherr, T. and Eckstein, D. (2014), "The impact of knowledge transfer and complexity on supply chain flexibility: a knowledge-based view", International Journal of Production Economics, Vol. 147, pp. 307-316.

Bode, C. and Wagner, S.M. (2015), "Structural drivers of upstream supply chain complexity and the frequency of supply chain disruptions", Journal of Operations Management, Vol. 36 No. 1, pp. 215-228.

Bozarth, C.C., Warsing, D.P., Flynn, B.B. and Flynn, E.J. (2009), "The impact of supply chain complexity on manufacturing plant performance", Journal of Operations Management, Vol. 27 No. 1, pp. 78-93.

Braunscheidel, M.J. and Suresh, N.C. (2009), “The organizational antecedents of a firm's supply chain agility for risk mitigation and response", Journal of Operations Management, Vol. 27 No. 2, pp. 119-140.

Carroll, G.R. and Hannan, M.T. (2000), The Demography of Corporations and Industries, Princeton University Press, Princenton.

Chi, T., Kilduff, P.P.D. and Gargeya, V.B. (2009), "Alignment between business environment characteristics, competitive priorities, supply chain structures, and firm business performance", International Journal of Productivity and Performance Management, Vol. 58 No. 7, pp. 645-669.

Christopher, M. (2000), "The agile supply chain", Industrial Marketing Management, Vol. 29 No. 1, pp. 37-44.

Christopher, M., Peck, H. and Towill, D. (2006), "A taxonomy for selecting global supply chain strategies”, International Journal of Logistic Management, Vol. 17 No. 2, pp. 277-287. 
Cohen, M.A. and Kouvelis, P. (2020), "Revisit of AAA excellence of global value chains: robustness, resilience, and realignment", Production and Operations Management, Vol. 30 No. 3, pp. 633-643, doi: 10.1111/poms.13305.

Defee, C.C., Williams, B., Randall, W.S. and Thomas, R. (2010), "An inventory of theory in logistics and SCM research", The International Journal of Logistics Management, Vol. 21 No. 3, pp. 404-489.

Dubey, R., Altay, N., Gunasekaran, A., Blome, C., Papadopoulos, T. and Childe, S.J. (2018), "Supply chain agility, adaptability and alignment: empirical evidence from the Indian auto components industry", International Journal of Operations and Production Management, Vol. 38 No. 1, pp. 129-148.

Eckstein, D., Goellner, M., Blome, C. and Henke, M. (2015), "The performance impact of supply chain agility and supply chain adaptability: the moderating effect of product complexity", International Journal of Production Research, Vol. 53 No. 10, pp. 3028-3046.

Erhun, F., Kraft, T. and Wijnsma, S. (2020), "Sustainable triple-A supply chains", Production and Operations Management, Vol. 30 No. 3, pp. 644-655, doi: 10.1111/poms.13306.

Fawcett, S.E. and Magnan, G.M. (2001), Achieving World-Class Supply Chain Alignment: Benefits, Barriers, and Bridges, Center for Advanced Purchasing Studies, Tempe.

Feizabadi, J., Maloni, M. and Gligor, D. (2019), "Benchmarking the triple-A supply chain: orchestrating agility, adaptability, and alignment”, Benchmarking: An International Journal, Vol. 26 No. 1, pp. 271-295.

Fisher, M.L. (1997), "What is the right supply chain for your product", Harvard Business Review, Vol. 75 No. 2, pp. 105-116.

Flynn, B.B., Huo, B. and Zhao, X. (2010), "The impact of supply chain integration on performance: a contingency and configuration approach", Journal of Operations Management, Vol. 28 No. 1, pp. 58-71.

Fynes, B., de Burca, S. and Voss, C. (2005), "Supply chain relationship quality, the competitive environment and performance", International Journal of Production Research, Vol. 43 No. 16, pp. 3303-3320.

Gimenez, C., van der Vaart, T. and van Donk, D.P. (2012), "Supply chain integration and performance: the moderating effect of supply complexity", International Journal of Operations and Production Management, Vol. 32 No. 5, pp. 583-610.

Gligor, D.M. (2016), "The role of supply chain agility in achieving supply chain fit", Decision Sciences, Vol. 47 No. 3, pp. 524-553.

Gligor, D.M. and Holcomb, M.C. (2014), "The road to supply chain agility: an RBV perspective on the role of logistics capabilities", International Journal of Logistics Management, Vol. 25 No. 1, pp. 160-179.

Gligor, D.M., Esmark, C.L. and Holcomb, M.C. (2015), "Performance outcomes of supply chain agility: when should you be agile?", Journal of Operations Management, Vols 33/34 No. 1, pp. 71-82.

Gligor, D., Russo, I., Maloni, M.J. and Goldsby, T.J. (2020), "The triple-a supply chain and strategic resources: developing competitive advantage", International Journal of Physical Distribution and Logistics Management, Vol. 50 No. 2, pp. 159-190.

Hair, J.F., Hult, G.T.M., Ringle, C.M. and Sarstedt, M. (2017), A Primer on Partial Least Squares Structural Equation Modeling (PLS-SEM), SAGE Publications, Los Angeles.

Hair, J.F., Risher, J.J., Sarstedt, M. and Ringle, C.M. (2019), "When to use and how to report the results of PLS-SEM", European Business Review, Vol. 31 No. 1, pp. 2-24.

Hallgren, M. and Olhager, J. (2009), "Lean and agile manufacturing: external and internal drivers and performance outcomes", International Journal of Operations and Production Management, Vol. 29 No. 10, pp. 976-999.

Heirati, N., O'Cass, A., Schoefer, K. and Siahtiri, V. (2016), "Do professional service firms benefit from customer and supplier collaborations in competitive, turbulent environments?", Industrial Marketing Management, Vol. 55, pp. 50-58. 
Hofmann, E. (2010), "Linking corporate strategy and supply chain management”, International Journal of Physical Distribution and Logistics Management, Vol. 40 No. 4, pp. 4256-4276.

Hoole, R. (2005), "Five ways to simplify your supply chain", Supply Chain Management: An International Journal, Vol. 10 No. 1, pp. 3-6.

Ketchen, D.J., Snow, C. and Hoover, V.L. (2004), "Research on competitive dynamics: recent accomplishments and future challenges", Journal of Management, Vol. 30 No. 6, pp. 779-804.

Ketchen, D.J., Rebarick, W., Hult, G.T. and Meyer, D. (2008), "Best value supply chains: a key competitive weapon for the 21stcentury", Business Horizons, Vol. 51 No. 3, pp. 235-243.

Kock, N. (2015), "Common method bias in PLS-SEM: a full collinearity assessment approach", International Journal of E-Collaboration, Vol. 11 No. 4, pp. 1-10.

Kock, N. (2020), WarpPLS User Manual: Version 7.0, ScriptWarp Systems, Laredo.

Lawrence, P.R. and Lorsch, J.W. (1967), Organization and Environment, Harvard University Press, Cambridge.

Lee, H.L. (2004), "The triple-A supply chain”, Harvard Business Review, Vol. 82 No. 10, pp. 102-112.

Lee, H.L. (2021), "The new AAA supply chain", Management and Business Review, Vol. 1 No. 1, pp. 173-176.

Lee, S.M. and Rha, J.S. (2016), "Ambidextrous supply chain as a dynamic capability: building a resilient supply chain", Management Decision, Vol. 54 No. 1, pp. 2-23.

MacCarthy, B.L., Blome, C., Olhager, J., Srai, J.S. and Zhao, X. (2016), "Supply chain evolution-theory, concepts and science", International Journal of Operations and Production Management, Vol. 36 No. 12 , pp. 1696-1718.

Machuca, J.A.D., Marin-Garcia, J.A. and Alfalla-Luque, R. (2021), "The country context in Triple-A supply chains: an advanced PLS-SEM research in emerging vs developed countries", Industrial Management and Data Systems, Vol. 121 No. 2, pp. 228-267.

Mak, H.Y. and Max Shen, Z.J. (2020), "When triple-A supply chains meet digitalization: the case of JD.com'sC2M model”, Production and Operations Management, Vol. 30 No. 3, pp. 656-665, doi: 10.1111/poms.13307.

Manuj, I. and Sahin, F. (2011), "A model of supply chain and supply chain decision making complexity", International Journal of Physical Distribution and Logistics Management, Vol. 41 No. 5, pp. 511-549.

Marin-Garcia, J.A., Alfalla-Luque, R. and Machuca, J.A.D. (2018), "A Triple-A supply chain measurement model: validation and analysis", International Journal of Physical Distribution and Logistics Management, Vol. 48 No. 10, pp. 976-994.

Mason-Jones, R., Naylor, B. and Towill, D. (2000), "Engineering the leagile supply chain”, International Journal of Agile Management Systems, Vol. 2 No. 1, pp. 54-61.

McCullen, P., Saw, R., Christopher, M. and Towill, D. (2006), "The F1 supply chain: adapting the car to the circuit-the supply chain to the market", Supply Chain Forum: An International Journal, Vol. 7 No. 1, pp. 14-23.

Moyano-Fuentes, J. and Martínez-Jurado, P. (2016), "The influence of competitive pressure on manufacturer internal information integration", International Journal of Production Research, Vol. 54 No. 22 , pp. $6683-6692$.

Porter, M.E. (1980), "Industry structure and competitive strategy: keys to profitability", Financial Analysts Journal, Vol. 36 No. 4, pp. 30-41.

Prater, E., Biehl, M. and Smith, M.A. (2001), "International supply chain agility - Tradeoffs between flexibility and uncertainty", International Journal of Operations and Production Management, Vol. 21 Nos 5/6, pp. 823-839.

Qi, Y., Zhao, X. and Sheu, C. (2011), "The impact of competitive strategy and supply chain strategy on business performance: the role of environmental uncertainty", Decision Sciences, Vol. 42 No. 2, pp. 371-389. 
Qi, Y., Huo, B., Wang, Z. and Yeung, H.Y.J. (2017), "The impact of operations and supply chain strategies on integration and performance", International Journal of Production Economics, Vol. 185, pp. 162-174.

Roh, J.P., Hong, P. and Min, H. (2014), "Implementation of a responsible supply chain strategy in global complexity: the case of manufacturing firms", International Journal of Production Economics, Vol. 147 No. Part B, pp. 198-210.

Roscoe, S., Eckstein, D., Blome, C. and Goellner, M. (2020), "Determining how internal and external process connectivity affect supply chain agility: a life-cycle theory perspective", Production Planning and Control, Vol. 31 No. 1, pp. 78-91.

Sacristán-Díaz, M., Garrido-Vega, P. and Moyano-Fuentes, J. (2018), "Mediating and non-linear relationships among supply chain integration dimensions", International Journal of Physical Distribution and Logistics Management, Vol. 48 No. 7, pp. 698-723.

Sebastiao, H.J. and Golicic, S. (2008), "Supply chain strategy for nascent firms in emerging technology markets", Journal of Business Logistics, Vol. 29 No. 1, pp. 75-91.

Serdarasan, S. (2013), "A review of supply chain complexity drivers", Computers and Industrial Engineering, Vol. 66 No. 3, pp. 533-540.

Sherehiy, B., Karwowski, W. and Layer, J.K. (2007), "A review of enterprise agility: concepts, frameworks, and attributes", International Journal of Industrial Ergonomics, Vol. 37 No. 5, pp. $445-460$.

Sousa, R. and Voss, C.A. (2008), "Contingency research in operations management practices", Journal of Operations Management, Vol. 26 No. 6, pp. 697-713.

Swafford, P.M., Ghosh, S. and Murthy, N. (2006), "The antecedents of supply chain agility of a firm: scale development and model testing", Journal of Operations Management, Vol. 24 No. 2, pp. 170-188.

Tachizawa, E.M. and Gimenez, C. (2010), "Supply flexibility strategies in Spanish firms: results from a survey", International Journal of Production Economics, Vol. 124 No. 1, pp. 214-224.

Teece, D.J., Pisano, G. and Shuen, A. (1997), "Dynamic capabilities and strategic management", Strategic Management Journal, Vol. 18 No. 7, pp. 509-533.

Tuominen, M., Rajala, A. and Möller, K. (2004), "How does adaptability drive firm innovativeness?", Journal of Business Research, Vol. 57 No. 5, pp. 495-506.

Whitten, G.D., Green, K.W. and Zelbst, P.J. (2012), "Triple-A supply chain performance”, International Journal of Operations and Production Management, Vol. 32 No. 1, pp. 28-48.

Wong, C.W.Y., Lai, K. and Bernroider, E.W.N. (2015), "The performance of contingencies of supply chain information integration: the roles of product and market complexity", International Journal of Production Economics, Vol. 165, pp. 1-11.

Wu, K., Tseng, M., Chiu, A.S.F. and Lim, M.K. (2017), "Achieving competitive advantage through supply chain agility under uncertainty: a novel multi-criteria decision-making structure", International Journal of Production Economics, Vol. 190, pp. 96-107.

Zhou, K.Z. and Li, C.B. (2010), "How strategic orientations influence the building of dynamic capability in emerging economies", Journal of Business Research, Vol. 63 No. 3, pp. 224-231. 
Please rate your degree of agreement with the following statements regarding the C2 agility, C3 adaptability and C4 alignment of your supply chain on the following scale: 1 = totally disagree; $2=$ disagree; $3=$ neutral; $4=$ agree; $5=$ totally agree

C2a Our supply chain can be adjusted to the specifications of the orders made by our customers

$\mathrm{C} 2 \mathrm{~b}$ If necessary, our supply chain can adjust its operations as required to execute our decisions

C2c Production planning has the capability to respond quickly to customers' changing needs

C2d Our supply chain can increase its short-term capacity when necessary

C2e Our supply chain can adjust/accelerate delivery times

C2f Our supply chain responds to customer demand

C2g* Our supply chain selects suppliers based on their results in terms of flexibility and responsiveness

C2h* Our supply chain structure often changes to cope with changing market conditions

C3a* Our production system is designed to accommodate changes in SC adaptability (Marin-Garcia et al., 2018) the demand volume

C3b* Our production system is designed to accommodate changes in the production mix

C3c We have a good understanding of where our production technology stands in terms of technology life cycles

C3d Our plant is continually on the leading edge of new technology in our industry

C3e We monitor economies around the world to detect potential new markets

C3f We monitor economies around the world to identify potential new suppliers

C3g* We are concerned about the needs of both our immediate customers and our end consumers

C3h* We have a very good understanding of our suppliers' distribution processes

C4a* Our senior managers repeatedly tell us that sharing supply chain risks and rewards with our customers is critical to our plant's success

C4b* Our senior managers repeatedly tell us that sharing supply chain risks and rewards with our suppliers is critical to our plant's success

C4c Our supply chain members have clearly defined goals in our supply chain

C4d We emphasise openness of communication in collaboration with our customers

$\mathrm{C} 4 \mathrm{e}$ We emphasise openness of communication in collaboration with our suppliers

C4f Data stored in different databases (i.e. order status) are consistent across the supply chain

$\mathrm{C} 4 \mathrm{~g}$ We should use unambiguous language and communication with our supply chain partners

$\mathrm{C} 4 \mathrm{~h} *$ Cooperating with our customers is beneficial to us

$\mathrm{C}_{4}{ }^{*}$ Cooperating with our suppliers is beneficial to us

$\mathrm{C} 4 \mathrm{j} \quad$ Our supply chain members understand our manufacturing capabilities

SC agility (Tachizawa and Gimenez, 2010; Q et al., 2011; Gligor et al., 2014)

SC alignment (Marin-Garcia et al., 2018) 
A.11. Please rate the competitive intensity of your industry on the following scale: 1 = totally disagree; $2=$ disagree; $3=$ neutral; $4=$ agree $; 5=$ totally agree

A11a We operate in a highly competitive industry

A11b Competitive pressures on us are extremely high

Competitive intensity (Hallgren and Olhager,

A11c Competitive movements in our market are rapid and 2009) unpredictable and no significant long-term differences can be observed in different companies' reactions

A11d We pay close attention to our competitors

A2 What is the approximate number of suppliers that your company has?

A7 What is the approximate number of customers that your company has?

SC complexity (based on Roth et al., 2014)

A.12. Please evaluate the following objectives according to their relative importance. Mark as absolutely crucial only if it helps to "win the order" from the customer in the market, beating out the competition. Evaluate the other objectives according to their relative importance on a scale of 1 to 5 where $1=$ the least important and $5=$ absolutely crucial

A12a Low prices

A12b Low manufacturing unit cost Cost leadership strategy (Hallgren and

A12c Ability to quickly change the product in the short term Olhager, 2009)

A12d Ability to vary the manufactured volume of the product in the Olhager, 2009) short term

Note(s): Items marked by an asterisk $\left(^{*}\right)$ were omitted from the construct during the measurement model analysis phase

\section{Corresponding author}

Pedro Garrido-Vega can be contacted at: pgarrido@us.es

For instructions on how to order reprints of this article, please visit our website: 